\title{
El silencio en el aula de ELE. Propuesta taxonómica y metodológica para su didáctica
}

\author{
Beatriz MÉNDEZ GUERRERO \\ Universitat de les Illes Balears \\ Departamento de Filología Española, Moderna y Clásica \\ beatriz.mendez@uib.es
}

Recibido: mayo 2013

Aceptado: julio 2014

\begin{abstract}
RESUMEN
El silencio tiene un gran valor comunicativo y cuenta, en cada cultura, con unos valores propios que lo motivan y unas funciones comunicativas particulares que lo caracterizan. Por este motivo, se hace imprescindible su tratamiento en el ámbito de la enseñanza de español como lengua extranjera (ELE) y es fundamental que todo estudiante de segundas lenguas conozca y aplique las normas que rigen estos signos no verbales en la lengua meta.

Actualmente, los actos silenciosos cuentan con un escaso reconocimiento curricular y rara vez son tratados en el aula de lenguas extranjeras. Esto está, en parte, motivado por la falta de repertorios consensuados y completos que recojan la mayor parte de las funciones comunicativas del silencio en la cultura española y, también, por no disponer el estudio del silencio todavía de una metodología clara que posibilite su incorporación al aula de español.

La intención de este trabajo es presentar una clasificación de las funciones comunicativas del silencio en la cultura española aplicable a la enseñanza de ELE y exponer una metodología que permita introducir de forma integrada y por niveles el silencio en la clase de español como segunda lengua.
\end{abstract}

Palabras clave: silencio, enseñanza de español como lengua extranjera, taxonomía, metodología, comunicación no verbal.

\section{Silence in the teaching of Spanish as a foreign language. A taxonomic and methodological approach}

\begin{abstract}
Silence has great communicative value and it gathers, in each culture, some unique qualities which bring it about and some particular communicative functions which characterize it. For this reason, it is essential that its treatment is accounted for when teaching Spanish as a foreign language (ELE) and also that every person learning Spanish as second language can get to know and apply the rules governing these non-verbal factors.

Currently, silent acts have little curricular recognition and they are rarely treated in the teaching of foreign languages. This, in part, is due to the lack of consensus and exhaustive repertoires that collect most of the communicative functions of silence in Spanish culture and also because the study of silence still does not have a clear methodology that enables its incorporation to Spanish lessons.
\end{abstract}


The aim of this paper is to present a classification of the communicative functions of silence in Spanish culture applicable to teaching ELE and to expose a methodology which allows introducing, in an integrated and tiered way, silence in the teaching of Spanish as a second language.

Keywords: silence, teaching Spanish as a foreign language, taxonomy, methodology, nonverbal communication.

\section{Le silence dans les cours d'ELE. Proposition taxonomique et méthodologique pour l'enseignement}

\section{RÉSUMÉ}

Le silence à une grande valeur communicative et, dans toutes les cultures, avec propres valeurs qui motivent et des particulières fonctions communicatives qui le caractérisent. Pour cette raison, il est essentiel son traitement dans le domaine de l'enseignement de l'espagnol comme langue étrangère (ELE) et il est fondamental que tout apprenant d'une deuxième langue connaisse et applique les règles régissant ces signes non verbaux dans la langue cible.

Actuellement, les actes silencieux ont une reconnaissance limitée dans les programmes d'études et rarement ils sont traités dans les cours de langues étrangère. Ceci est dû, en partie, à l'absence de répertoires consensuels et complets qui recueillent la plupart des fonctions communicatives des silences dans la culture espagnole et, d'autre part, pour ne pas compter celui-ci d'une étude de la méthodologie claire qui permette son incorporation dans les cours d'espagnol.

Le but de ce travail est de présenter une classification des fonctions communicatives du silence dans la culture espagnole applicable à l'enseignement de ELE et, d'exposer une méthodologie qui permette d'introduire de manière intégré et hiérarchisé le silence dans les cours d'espagnol comme deuxième langue.

Mots-clé: silence, enseignement d'espagnol comme langue étrangère, taxonomie, méthodologie, la communication non-verbale.

SUMARIO: 1. Introducción. 2. La importancia del silencio en la adquisición de lenguas extranjeras. 3. Las funciones comunicativas del silencio en la cultura española. 4. Propuesta metodológica para el tratamiento curricular del silencio en el aula de ele. 5. Conclusiones. 6. Referencias bibliográficas.

\section{INTRODUCCIÓN}

La necesidad de entendernos y comunicarnos en esta era globalizada ha llevado a los estudiosos en la enseñanza de segundas lenguas a convencerse de que los esfuerzos han de centrarse en dotar a los estudiantes de lenguas extranjeras (LE) de los elementos verbales y no verbales necesarios para comunicarse interculturalmente y para poder interactuar con otros hablantes en cualquier situación comunicativa. El fulgurante asentamiento del concepto de competencia 
comunicativa $^{1}$ ha abierto la puerta al tratamiento del componente cultural y a la enseñanza de los signos no verbales en el aula de español como lengua extranjera (ELE). Su posterior inclusión en los planes curriculares institucionales (MCER y PCIC $)^{2}$ y su incorporación en muchas programaciones de aula han contribuido también a que se diseñen metodologías y se ideen recursos que permitan insertar y trabajar los signos no verbales en el aula de español. Por este motivo, la enseñanza de los mecanismos no verbales de la comunicación se ha convertido, en los últimos tiempos, en un elemento indispensable en la enseñanza de lenguas y ya no se duda de que sea conditio sine qua non para la completa adquisición de la competencia comunicativa en la lengua extranjera. Cestero $(1998,7)$ se ha referido a esta cuestión en muchos de sus trabajos:

Desde hace ya algún tiempo, los estudios de la lengua y la comunicación son conscientes de que la enseñanza y el aprendizaje de una lengua extranjera supone mucho más que la adquisición de una competencia lingüística por parte del estudiante. Es necesario enseñar y aprender a comunicarse en la lengua meta y, para ello, el conocimiento del sistema lingüístico, por muy bueno y completo que sea, no es suficiente: se debe atender también a la competencia comunicativa. Una parte importante de esa competencia comunicativa son los sistemas de comunicación no verbales.

El silencio - como elemento constitutivo de la comunicación no verbal- también ha de ser atendido en el aula de español como lengua extranjera (ELE). Estudios recientes en el campo de la no verbalidad apuntan a que los planes curriculares institucionales y los manuales o programaciones de ELE se han inclinado por ignorar este signo paralingüístico en sus planteamientos pedagógicos $\mathrm{y}$, en consecuencia, han optado por excluir su tratamiento en la clase de español (Méndez, en prensa). Este hecho, como se explicará, se ha relacionado en ocasiones con la escasa tradición que tiene la exploración del silencio en los estudios de la comunicación, con la dificultad que entraña inferir sus funciones, valores y significados comunicativos, con la gran diversidad taxonómica existente y con la falta de una metodología clara que permita su estudio y sistematización (Poyatos, 1994; Cestero, 1999; Méndez, 2011).

1 Entendida como "la capacidad de comportarse eficaz y adecuadamente en una determinada comunidad de habla, respetando tanto las reglas gramaticales como las reglas de uso de la lengua, relacionadas con el contexto sociohistórico y cultural en el que tiene lugar la comunicación" (Gutiérrez, 2007, 16).

2 Marco común europeo de referencia para las lenguas: aprendizaje, enseñanza y evaluación (Consejo de Europa, 2002) y Plan curricular del Instituto Cervantes. Niveles de referencia para el español (Instituto Cervantes, 2006) respectivamente. 
En las páginas que siguen, se expondrán algunas de las razones por las que pensamos que el silencio ha de ser incluido en la enseñanza de ELE, se propondrá también una clasificación funcional de los silencios más frecuentes en la cultura española y se planteará, finalmente, una metodología estable que haga posible la incorporación de estos signos en las programaciones curriculares de enseñanza de lenguas.

\section{LA IMPORTANCIA DEL SILENCIO EN LA ADQUISICIÓN DE LENGUAS EXTRANJERAS}

El silencio se ha descrito como un elemento con alto valor comunicativo y sociocultural. Esta cuestión ha llevado a estudiarlo desde distintas disciplinas y culturas con el fin de determinar su funcionamiento y establecer sus significados y valores. De los estudios realizados hasta el momento se desprende que los actos silenciosos no son elementos universales, pues cuentan en cada cultura con unos valores propios que los motivan y con unas actuaciones particulares que los caracterizan (Cestero, 2004; Vivas, 2011; Camargo y Méndez, 2013; Méndez, $2013 a)^{3}$. En algunas sociedades occidentales -como la mediterránea- ocurre que estos elementos pueden resultar molestos para los hablantes y que, por ello, son poco frecuentes en los intercambios comunicativos (Haverkate, 1994; Poyatos, 1994; Cestero, 2000; Mateu, 2001; Vivas, 2011; Camargo y Méndez, en prensa). Esta "aprensión" hacia el silencio contrasta con la alta tolerancia que parece tener este signo paralingüístico en otras culturas orientales o del norte de Europa (Morsbach, 1988; Sajvaara y Lehtonen, 1997). Hay autores para los que, además, existe una clara relación entre la presencia del silencio y las culturas de cortesía negativa y la ausencia de silencio y las culturas de cortesía positiva ${ }^{4}$ (Haverkate, 1994; Poyatos, 1994; Sifianou, 1997; Contreras, 2008; Méndez, en prensa).

Ante la constatación de que existen diferencias interculturales en los silencios de las distintas culturas, se hace pues imprescindible para todo estudiante de lengua extranjera conocer y aprender las normas que rigen los signos no verbales en la lengua meta ${ }^{5}$. Para Vivas (2011), aprender estas reglas forma parte del proceso de

\footnotetext{
${ }^{3}$ No se discute aquí sobre la universalidad del silencio en el sentido de que exista en todas las culturas, sino sobre las notables diferencias que presenta en sus formas y realizaciones pragmáticas dependiendo de la cultura sobre la que se centre la atención.

${ }^{4}$ Términos acuñados por Brown y Levinson ([1978] 1987) que se refieren, en el caso de las culturas de cortesía positiva, al sentimiento de solidaridad, afiliación o acogimiento que predomina en los intercambios comunicativos de los hablantes de esas sociedades $\mathrm{y}$, en las culturas de cortesía negativa, al sentimiento de independencia o libertad individual que presenta frecuentemente en la interacción el grupo de hablantes de esa comunidad.

${ }_{5}^{5}$ Así pues, ha de entenderse que la cultura española comprende actuaciones comunicativas "generalizables", al menos en parte, y distintas a las producidas en otras culturas que
} 
"aculturación" que ha de realizarse si se quiere alcanzar la competencia comunicativa en la lengua extranjera (Vivas, 2011, 43). El proceso de "aculturación" al que se refiere la autora, como es sabido, se lleva a cabo de forma espontánea en hablantes nativos, pero no ocurre así con los estudiantes de segundas lenguas que desconocen los aspectos culturales de la lengua que se está adquiriendo y a los que la simple interacción con los hablantes nativos no les basta para asimilar los signos culturales verbales y no verbales de la lengua extranjera (Méndez, en prensa).

No debe olvidarse tampoco que la transferencia de las normas verbales y no verbales de la lengua de origen (o de cualquier otra lengua sobre la que se tenga conocimiento) a la lengua meta es algo frecuente en los estudiantes de lenguas extranjeras y que estas cuestiones desembocan en habituales presuposiciones o sobreentendidos comunicativos que conducen al error. De lo anterior, se deduce que será solo el estudio de los elementos culturales (verbales y no verbales) de la segunda lengua en todos los niveles de aprendizaje lo que permitirá superar o, al menos, minimizar el impacto que causan las transferencias, choques o errores pragmáticos en las relaciones sociales de los hablantes (Cestero, 2004; Méndez, 2011; Méndez, en prensa). Y que, por tanto, será necesario asimismo establecer unos mecanismos o una metodología clara que permitan, en primer lugar, conocer las propiedades y funciones de los silencios en la cultura que se pretende enseñar y, a continuación, proponer un sistema para su incorporación en el proceso de enseñanza-aprendizaje de lenguas extranjeras.

\section{LAS FUNCIONES COMUNICATIVAS DEL SILENCIO EN LA CULTURA ESPAÑOLA}

El concepto de función comunicativa ha estado ampliamente atendido $\mathrm{y}$ respaldado en la adquisición de lenguas extranjeras en las últimas décadas. El objetivo fundamental de este planteamiento es que el alumno pueda llegar a comunicarse en la lengua que está aprendiendo en cualquier tipo de situación, a partir de la integración de las cuatro destrezas y "teniendo en cuenta los objetivos pragmáticos y $[\ldots]$ contextos comunicativos similares a los que se puede encontrar en la realidad" (Gutiérrez, 2007, 23). La selección de las funciones comunicativas que se van a enseñar en el aula de ELE y su secuenciación didáctica se basa, por tanto, en criterios de "eficacia comunicativa y en los objetivos fijados en el programa" (Gutiérrez, 2007, 49). Estos aspectos dependerán de los contextos situacionales, los eventos comunicativos, los roles sociales y las actividades de uso en las que se prevé que habrán de desenvolverse los alumnos. Lo fundamental del enfoque funcional es llegar a conjugar el aprendizaje del elemento lingüístico con

requieren de su enseñanza-aprendizaje a los no nativos. Este hecho coincide con lo propuesto por Ambadiang y García Parejo (2006). 
la realización funcional. En el caso del silencio, por consiguiente, tendrán que seleccionarse primero las funciones comunicativas que cumple el silencio en la cultura meta y, a continuación, se presentarán en el aula las realizaciones paralingüísticas o exponentes silenciosos con las que los hablantes nativos llevan a cabo dicha función comunicativa ${ }^{6}$.

Numerosos estudios sobre comunicación no verbal y su aplicación a la enseñanza de lenguas extranjeras han propuesto la incorporación en los planes curriculares de repertorios lingüísticos y culturales (Poyatos, 1994, 2002, 2006) o inventarios de signos no verbales (Cestero, 1998, 1999, 2004) que permitan el tratamiento de los signos no verbales en el aula de ELE. Pero, desde sus orígenes, los estudios sobre la comunicación no verbal y muy especialmente los que versan sobre el silencio se han visto en la necesidad de superar algunos problemas tipológicos y metodológicos que han llevado a retrasar su análisis desde un punto de vista pragmático y conversacional (Méndez, 2011). En este sentido, Cestero $(2006,58)$ ya avisaba de la falta de una base teórica consolidada en los estudios de la comunicación no verbal y se refería a esta cuestión como otro de los mayores inconvenientes a la hora de abordar su análisis:

El conocimiento que hoy en día tenemos sobre comunicación no verbal es relativamente escaso y muy fragmentario. Tanto es así que, a comienzos del siglo XXI, aún no contamos con una base teórica sólida que nos permita describir y explicar con propiedad y detalle qué es la comunicación no verbal, qué sistemas la integran, cuáles son sus signos y cómo funcionan, debido, fundamentalmente, a la dificultad metodológica que entraña su investigación y a la poca y heterogénea tradición que tiene su estudio.

A esto se ha unido la gran diversidad tipológica y taxonómica que existe en torno a los actos silenciosos (Sacks et al., 1974; Saville-Troike, 1985; Gallardo, 1993; Jaworski, 1993; Bilmes, 1994; Poyatos, 1994; Kurzon, 1997; Cestero, 1999; Nakane, 2005; Ephratt, 2008), la cual es fruto habitualmente de la reflexión o de la introspección del investigador y se basa exclusivamente en ejemplos ficticios y privados de contexto. Por ende, muchas de estas clasificaciones no están en consonancia con lo promulgado por los planteamientos teóricos de algunas investigaciones en pragmática (Camargo, 2006; Leonetti, 2008; Escandell, 2011) que en los últimos años abogan por cimentar los estudios sobre los aspectos verbales y no verbales de la interacción en ejemplos reales, situados en contexto y pertenecientes a un corpus de lengua oral (Camargo, 2006, 81-83):

${ }^{6}$ La enseñanza de los silencios, como se verá en las páginas que siguen, tendrá que integrarse al resto de contenidos verbales y no verbales del curso y deberá adecuarse al nivel de conocimientos del grupo de alumnos con el que se está trabajando. 
La pragmática, especialmente orientada hacia el estudio de la relación entre los condicionantes sociales y culturales que determinan los usos del lenguaje, no debería prescindir de ejemplos basados en intercambios comunicativos reales. [...] Este proceder metodológico, propio de la sociolingüística y del análisis de la conversación, sigue siendo una asignatura pendiente dentro de los estudios de pragmática, en los que se suele recurrir a reconstrucciones o recreaciones del propio investigador.

Además, a los devenires tipológicos y metodológicos ya referidos ha de sumarse la dificultad que entraña establecer o inferir significados claros para los actos silenciosos que se producen en las interacciones cotidianas. Con esto, aún parece más justificada la necesidad de abordar su estudio desde el análisis de corpus de conversaciones reales. En esta línea, Cestero (2004, 606-609) propone un método de trabajo cuya finalidad es obtener inventarios de signos no verbales "homogéneos, completos y detallados, siguiendo las cuatro fases propias de la investigación empírica" y que consiste en (1) seleccionar y constatar el objeto de estudio, (2) recoger el material, (3) analizar el material y (4) presentar los resultados.

En este trabajo se ha recurrido a un repertorio o clasificación que hemos presentado en trabajos anteriores ${ }^{7}$ sobre las funciones pragmáticas del silencio en la conversación coloquial española. Concretamente, la taxonomía se basa en la observación y análisis de los actos silenciosos producidos por un grupo de 10 jóvenes españoles (menores de 25 años) durante 15 horas de conversaciones espontáneas en contextos cotidianos e informales. Los resultados de la investigación sugieren que en la cultura española existen, al menos, cuatro tipos de silencios y que estos, a su vez, cuentan con distintas funciones comunicativas:

\begin{tabular}{|c|c|c|c|}
\hline $\begin{array}{c}\text { SILENCIOS } \\
\text { DISCURSIVOS }\end{array}$ & $\begin{array}{c}\text { SILENCIOS } \\
\text { ESTRUCTURADORES }\end{array}$ & $\begin{array}{c}\text { SILENCIOS } \\
\text { EPISTEMOLÓGICOS Y } \\
\text { PSICOLÓGICOS }\end{array}$ & $\begin{array}{c}\text { SILENCIOS } \\
\text { NORMATIVOS }\end{array}$ \\
\hline $\begin{array}{l}\text { Marcadores de } \\
\text { acuerdo o } \\
\text { desacuerdo }\end{array}$ & $\begin{array}{l}\text { Distribuidores de } \\
\text { turno }\end{array}$ & Cognitivos & $\begin{array}{l}\text { Por convenciones } \\
\text { situacionales }\end{array}$ \\
\hline $\begin{array}{l}\text { Intensificadores o } \\
\text { atenuadores }\end{array}$ & $\begin{array}{l}\text { Marcadores de } \\
\text { respuesta despreferida }\end{array}$ & $\begin{array}{l}\text { Indicadores de } \\
\text { cautela }\end{array}$ & $\begin{array}{c}\text { Por convenciones } \\
\text { sociales }\end{array}$ \\
\hline
\end{tabular}

\footnotetext{
${ }^{7}$ Nos estamos refiriendo, concretamente, a la taxonomía presentada por Camargo y Méndez (2013), Camargo y Méndez (en prensa) y Méndez (2013a, 2013b, en prensa). Se ha decidido seguir esta taxonomía por formar parte de un estudio empírico, basado en informantes españoles, en el que se han analizado intercambios comunicativos reales.
} 


\begin{tabular}{|c|c|c|c|}
\hline $\begin{array}{c}\text { Indicadores de } \\
\text { engaño o } \\
\text { enmascaramiento }\end{array}$ & $\begin{array}{l}\text { Producidos por } \\
\text { errores de } \\
\text { coordinación }\end{array}$ & Emocionales & $\begin{array}{c}\text { Por convenciones } \\
\text { culturales }\end{array}$ \\
\hline Argumentativos & $\begin{array}{c}\text { Dinamizadores de la } \\
\text { conversación }\end{array}$ & Transgresores & \\
\hline $\begin{array}{l}\text { Humorísticos e } \\
\text { irónicos }\end{array}$ & $\begin{array}{c}\text { Indicadores de } \\
\text { petición de atención o } \\
\text { apoyo }\end{array}$ & & \\
\hline
\end{tabular}

Taxonomía de las funciones pragmáticas del silencio (Camargo y Méndez, 2013, en prensa; Méndez 2013a, 2013b, en prensa)

Tipo 1: Silencios discursivos: actúan como indicadores discursivos que guían las inferencias de los participantes y que ponen de manifiesto una especial orientación o sentido del acto comunicativo. Su papel no es otro que el de señalar la función comunicativa que se está expresando en la interacción (disentir, asentir, mostrar acuerdo, afirmar, atenuar, intensificar, reformular, ironizar...). Entre sus funciones se incluyen las de mostrar acuerdo o desacuerdo, intensificar o atenuar, indicar engaño o enmascaramiento, argumentar y humorizar o ironizar.

- Marcadores de acuerdo o desacuerdo: el silencio puede actuar como un indicador de conformidad o disensión del acto comunicativo que se va a producir dependiendo del contexto y del tipo de relación social que exista entre los interlocutores.

\section{(A) Ejemplo de silencio marcador de desacuerdo [CE.2.H0;H3] (468-472) ${ }^{8}$}

[H0 (mujer) y H3 (mujer) son amigas, tienen entre 20 y 25 años. Tema: hablan de lo complicado que es circular en coche por las grandes ciudades].

${ }^{8}$ Entiéndase que en cada ejemplo serán únicamente objeto de análisis los silencios destacados en negrita. Dichos ejemplos proceden del corpus de 15 horas en el que se basan los estudios ya referidos a los que pertenece la taxonomía. La forma en la que se presentan los silencios se corresponde con las convenciones de PRESEEA (2008) $<$ http://preseea.linguas.net/Portals/0/Metodologia/Marcas_etiquetas_minimas_obligatorias_ 1_2.pdf $>$ y es la siguiente: tres barras y un número entre paréntesis que indica los segundos que dura dicho silencio: ///(2) (silencio de 2 segundos de duración). Las pausas con una duración de entre 0,5 y 1 segundo se representarán con doble barra: // y las que no lleguen a 0,5 se presentarán con una única barra: /. El resto de convenciones de transcripción son las que siguen: _ Solapamientos, (:) Alargamientos, (-) Truncamiento o sílaba cortada, (¡!) Tono animado, (?) Pasajes inciertos en la grabación, (<risas= especificación del emisor $>$ ) Risas, (“") Citas o fragmentos en estilo directo. 
H0: yo lo que sé es que cada vez que vuelvo a casa me paso tres cuartos de hora metida en un atasco// estoy ya desesperada

H3: bueno///(1,5) todo depende de la ruta que sigas///(2) yo tardo bastante menos y la distancia viene a ser la misma

- Intensificadores o atenuadores: los actos silenciosos también se utilizan con frecuencia en la cultura española para maximizar o minimizar la fuerza ilocutiva de la enunciación.

(B) Ejemplo de silencio intensificador [CE.2.H0;H3] (202-205)

[H0 (mujer) y H3 (mujer) son amigas, tienen entre 20 y 25 años. Tema: hablan de lo despistada que es $\mathrm{H} 3$ ].

H3: ¡madre mía!///(2) ¡Con la de veces que he habré pasado por aquí!///(1) y yo sin fijarme en el garito ese

H0: yo alucino contigo/ chica// no puede ser que no lo hayas visto hasta ahora

- Indicadores de engaño o enmascaramiento: en otras ocasiones, los hablantes recurren a la ocultación o al enmascaramiento de sus pensamientos o mensajes a través del silencio.

(C) Ejemplo de silencio por enmascaramiento [CE.5.H0;H6] (750-754)

[H0 (mujer) y H6 (hombre) son amigos, tienen entre 20 y 25 años. Tema: hablan de los planes que tienen para el fin de semana, H6 ya ha quedado pero no se lo dice a $\mathrm{H} 0]$.

H0: hombre// yo la idea es que nos vayamos a tomar algo por ahí y que no se nos haga muy tarde tampoco// más que nada para poder aprovechar también la mañana del sábado sin andar hechos polvo

H6: ya// uff:/ pues yo: es que:///(1,5) no sé que haré///(1) igual no salgo///(1)

- Argumentativos: otra función discursiva es la que trata de explicar, aclarar, reformular o rectificar el mensaje tras la ausencia de habla.

(D) Ejemplo de silencio argumentativo [CE.4.H0;H5] (949-962)

[H0 (mujer) y H5 (hombre) son amigos, tienen entre 20 y 25 años. Tema: hablan de algunos cambios evolutivos que ha sufrido la lengua española].

H5: la entonación y todo esto//y eso básicamente va: cambiando palabras/ pero por por la entonación ¿no?/ por ejemplo///(1) igual que hayan podido///(1) como los apellidos que hay/ por ejemplo mi apellido es Monsalves pero puedes encontrar Monsalves/ Monsalvez/ Mozalvez

HO: ya 
- Humorísticos e irónicos: los actos humorísticos e irónicos, además de apoyarse en incongruencias, dobles sentidos, elementos léxicos, prosodia y quinésica, lo hacen también en aspectos paralingüísticos como el silencio.

(E) Ejemplo de silencio irónico [CE.1.H0;H1;H2] (45-52)

[H0 (mujer), H1 (mujer) y H2 (mujer) son amigas, tienen entre 20 y 25 años. Tema: hablan de un simulacro de robo y bomba que han presenciado en su lugar de trabajo].

H2: "que he puesto una bomba, que no me toques las narices"// ha sido lo mejor porque estaba $\mathrm{P} /$ yo con $\mathrm{L}$ me estaba partiendo

H1: $\quad$ eh pero iqué guay tío!

H2: "que he sido trabajadora de aquí y me habéis puteado y ahora os he puesto una bomba"

H0: y ella "observaciones, dos puntos, exempleada" (risas= H0)

H1: ///(2) real como la vida misma///(1) yo lo voy a hacer

H2: y yo

Tipo 2: Silencios estructuradores: responden a reglas o principios que organizan o estructuran la conversación, pues como es sabido la conversación se rige por reglas no obligatorias, pero que presentan opciones o preferencias y se organizan de forma sistemática. Estos silencios incluyen las funciones de distribuir el turno, marcar respuesta despreferida, indicar errores de coordinación, dinamizar la conversación o cambiar el tema y mostrar petición de atención o apoyo.

- Distribuidores de turno: el silencio es también uno de los mecanismos de los que dispone la conversación para indicar el cambio de turno de palabra.

(F) Ejemplo de silencio por distribución de turno [CE.6.H0;H7] (349-357)

[H0 (mujer) y H7 (hombre) son amigos, tienen entre 20 y 25 años. Tema: hablan del color de pelo de H0].

H7: para mi eres morena///(1)

H0: y si me apuras también distingo el castaño medio eh

H7: yo hay casos que veo más discutibles/ pero a ti se te ve claro que eres morena///(1)

H0: yo estoy convencida de que no// no tengo el pelo negro/tengo el pelo

H7:

negro negro/ no lo tiene nadie

pero es que

H0: ¡que sí tío!/ ¡mi madre! /lo tenía///(1)

H7: es verdad/ tu madre lo tiene más negro

- Marcadores de respuesta despreferida: las ausencias de habla actúan, en ocasiones y siguiendo la organización de la preferencia de los enunciados, 
como anticipadores de una posible respuesta despreferida o con la segunda parte de un par de adyacencia que no coincide con lo esperado ${ }^{9}$.

(G) Ejemplo de silencio por respuesta despreferida [CE.6.H0;H7] (678-679)

[H0 (mujer) y H7 (hombre) son amigos, tienen entre 20 y 25 años. Tema: están tomando algo y $\mathrm{H} 0$ tiene la sensación de que $\mathrm{H} 7$ quiere irse].

H0: que si estás cansado nos vamos

H7: $/ / /(1,5)$ es que no sé qué me pasa hoy que tengo el día cruzao

- Producidos por errores de coordinación: cuando la alternancia de turnos no se realiza de forma armoniosa las interrupciones, solapamientos y silencios suelen cobrar gran importancia.

(H) Ejemplo de silencio por error de coordinación [CE.3.H0;H4] (749-759)

[H0 (mujer) y H4 (hombre) son amigos, tienen entre 20 y 25 años. Tema: hablan de la profesión de H4].

H0: y lo mismo cuando cantas en un coro// que tienes otra voz a lo mejor por debajo y tú ya no sabes cuándo tienes que entrar (risas= TODOS) y es un lío y: ¡ah:! ¡terrible!

H4: ya pero eso es acostumbrarte///(1) es que eso://(1) es normal que te pase// pero cuando llevas muchos años tocando no:// es más cuando llevas muchos años tocando/ si no escuchas la otra voz// ya es cuando tú dices///(1,5) hey hey: que aquí

HO:

que aquí pasa

algo

H4: sí

H0: voy yo fuera///(1,5) y claro

H4: incluso:///(1) cuando tú:// nosotros contamos compases ino?///(1) lo sabes ¿no? lo de: uno// dos// tres

- Dinamizadores de la conversación: entre las señales que indican un cambio de tema o tópico en la conversación también se halla el silencio.

${ }^{9}$ Como se sabe, los pares de adyacencia son enunciados pareados (pregunta-respuesta, oferta-aceptación, saludo-saludo...) producidos por hablantes diferentes, ordenados como una primera y una segunda parte de un intercambio y organizados de manera que la primera parte requiere de la segunda (Levinson, 1989, 290). Ante elementos de este tipo, pueden aparecer respuestas preferidas o despreferidas. El principio de organización de preferencia recomienda las segundas partes no marcadas o respuestas preferidas (Levinson, 1989, 294). Pero, en ocasiones, los hablantes optan por segundos turnos despreferidos que no se ajustan a las expectativas del oyente, a esas actuaciones se les llama respuestas despreferidas (Levinson, 1989, 321). 
(I) Ejemplo de silencio dinamizador de la conversación [CE.2.H0;H3] (678685)

[H0 (mujer) y H3 (mujer) son amigas, tienen entre 20 y 25 años. Tema: hablan de sus hábitos y costumbres].

H0: ¡ay! no me apetece comer comida basura otra vez// ando siempre mala del estómago// me he acostumbrado este año a malcomer// como iba corriendo del curro a clase y comía por el camino si es que comía//y y estoy chunga chunga del estómago desde hace tiempo// no me apetece// comer aquí// así que me parece que me pillaré un bocata de los de: arriba/ un sándwich

H3: bueno/ los de arriba están buenos/ a mí me gustan///(1) madre mía que yo: me tengo que poner a estudiar

- Indicadores de petición de atención o apoyo: el silencio también puede realizarse para solicitar la atención del interlocutor sobre el mensaje que se está comunicando o para pedirle que apoye su discurso.

(J) Ejemplo de silencio por petición de atención o apoyo [CE.3.H0;H4] (536-538)

[H0 (mujer) y H4 (hombre) son amigos, tienen entre 20 y 25 años. Tema: hablan de las diferencias comunicativas que perciben entre mujeres y hombres].

H0: ipero es porque hay falta de comunicación H4!/ ¡no es una sensación!/ ¡si tú no hablas y hablo yo sola como con una pared!/ ¿tú qué quieres que haga?/ iyo me molesto!

H4: pero a ver hay cosas que ya se dicen solas///(1,5) ¿sabes?

Tipo 3: Silencios epistemológicos y psicológicos: se caracterizan por tener un alto componente psicológico, emocional y cognitivo, pues se ocupan de expresar la vacilación, cautela, reflexión o el desconocimiento del hablante así como de trasmitir o indicar su estado emocional. En este grupo se enmarcan las funciones comunicativas del silencio que indican reflexión o vacilación (llamadas también funciones cognitivas), cautela, emociones o sentimientos y transgresiones $\mathrm{o}$ resistencias.

- Cognitivos: en momentos de desconocimiento, duda o reflexión, el silencio con frecuencia aparece en la interacción.

(K) Ejemplo de silencio cognitivo [CE.6.H0;H7] (1474-1480)

[H0 (mujer) y H7 (hombre) son amigos, tienen entre 20 y 25 años. Tema: hablan del precio de la comida en el extranjero].

H7: no no/ no/ era otra cosa que era de: España// no sé por qué/ no/ tomates eran de España/ eran baratos

H0: ¿qué llamas barato?// ¿un euro y medio? 
H7: no/ era más barato que aquí/ no me acuerdo/ no sé/ pero yo es que ahora no compro///(1) no los compro yo ahora///(1) no no sé a qué precio están ahora///(1) los de "ramallet" son carísimos/ pero allí no había///(4)

H0: qué curioso

- Indicadores de cautela: la contención de algunas opiniones, pensamientos o voluntades también lleva a los hablantes a recurrir al silencio.

(L) Ejemplo de silencio por cautela [CE.6.H0;H7] (1474-1480)

[H0 (mujer) y H7 (hombre) son amigos, tienen entre 20 y 25 años. Tema: hablan del encuentro casual que tuvo $\mathrm{H} 7$ con una conocida común].

H0: ¡ah/ bueno! Ella llevaba siempre coleta/ ¿no?//

H7: sí

H0: y muy tirante/ llevaba el pelo liso ella/ porque no debían gustarle sus rizos// era en esa etapa en la que a nadie nos gustaban nuestros rizos

H7: ya pero/ ¿no era como súper?// a ver///(1,5) era como más///(1) a ver sin caer/ sin ser/ sin pasarse pero yo la veía como///(1) machorra no pero como más tirada///(1) yo la vi súper pija y claro ni la había conocido y súper maquillada

- Emocionales: cuando la situación es desconcertante o emocionalmente muy intensa también se puede optar por callar.

(M) Ejemplo de silencio emocional [CE.3.H0;H4] (978-983)

[H0 (mujer) y H4 (hombre) son amigos, tienen entre 20 y 25 años. Tema: hablan de la relación sentimental que $\mathrm{H} 4$ acaba de cerrar].

H0: hace más de tres meses// la echas de menos ¿verdad?

H4: uff:///(3) no te lo puedes ni imaginar

H0: yo sé que es duro/ que estás pasando por un mal momento// está todo muy reciente/ es normal// pero tienes que reponerte y empezar a salir más

H4: pero es que///(2) no puedo///(1) de verdad que no puedo

- Transgresores: son aquellos silencios que están más encaminados a la resistencia o subversión pasiva e indirecta en un intento deliberado de no cooperar.

(N) Ejemplo de silencio transgresor [CE.1.H0;H1] (978-983)

[H0 (mujer) y H1 (mujer) son amigas, tienen entre 20 y 25 años. Tema: H0 plantea la posibilidad de recoger la mesa después de comer].

H0: deberíamos recoger la mesa/mira qué hora es y lo tenemos todo por medio

H1: $/ / /(2)$

H0: ;oye!// ¡que te estoy hablando!

H1: ///(2) 
Tipo 4: Silencios normativos: están fuertemente regidos por las convenciones extralingüísticas, ya que se basan en un sistema de reglas, normas y rituales de un grupo de hablantes determinado. De este modo, se fundamentan en los principios y valores que los hablantes aceptan y practican en sus interacciones diarias al considerarlos idóneos y pertinentes. Estos silencios se aglutinan en silencios por convenciones situacionales, sociales y culturales.

- Por convenciones situacionales: los silencios en ocasiones están condicionados por el contexto, pues se ha consensuado que se utilicen en ciertos lugares o situaciones comunicativas.

(O) Ejemplo de silencio por convenciones situacionales [CE.1.H0;H1;H2] (978-983) [H0 (mujer), H1 (mujer) y H2 (mujer) son amigas, tienen entre 20 y 25 años. Tema: a lo lejos ven a unos amigos y $\mathrm{H} 2$ decide llamarlos por teléfono].

H0: ¿pero esa no es N?/ la del pantalón verde

H1: sí

H2: sí sí sí// espera que le llamo a $\mathrm{P} /$ le hago una perdida

H0: ¡hostia!/ Que estamos aquí que nos// yo qué sé que se acerquen ¿no?// N/ no sé nada de ella desde ha-// bueno desde que:

H2: no encuentro el móvil

H0: no ya no

H1: ya no

H0: ya están ahí en el coche tía

H2: a ver si lo coge (llamando por teléfono)

H0: ///(6) ¿qué?

H1: no vuelven ¿no?

H2: dice que os dé un beso

- Por convenciones sociales: otras veces son las convenciones sociales (relación social muy estrecha entre los interlocutores en la que se tolera más el silencio o asimetrías sociales $)^{10}$ las que tienen mayor peso y causan la aparición del silencio.

(P) Ejemplo de silencio por convenciones sociales [CE.2.H0;H3] (978-983)

[H0 (mujer) y H3 (mujer) son amigas, tienen entre 20 y 25 años. Tema: hablan de una anécdota acaecida a $\mathrm{H} 0]$.

H0: me acordé de ti el otro día

\footnotetext{
${ }^{10}$ Sobre la influencia que ejercen la relación social de los hablantes y el contexto en la recurrencia al silencio en la conversación española pueden consultarse los trabajos de Haverkate (1994), Camargo y Méndez (2013), Méndez (2013a, en prensa).
} 
H3: ///(1,5)

H0: resulta que en el curro hay una chica se te parece mucho y hace un par de días me la crucé y en ese momento no lo pensé y me dije “¡la leche! ¿Esa es H3? ¿Qué hace aquí?" (RISAS= TODAS)

H3: anda que:/ vaya tela/ tía/ vaya tela

- Por convenciones culturales: existen tópicos conversacionales que en determinadas culturas se consideran temas tabú y que son portadores de numerosos silencios en la interacción.

(Q) Ejemplo de silencio por convenciones culturales [CE.1.H0;H2] (779-782)

[H0 (mujer) y H2 (mujer) son amigas, tienen entre 20 y 25 años. Tema: hablan de la bulimia].

H0: ¡buah:!// pero es que:///(1) es complicado ¿eh?// yo:///(1) hay que ponerse en su piel

H2: ya tía// pero es que vomitarlo todo///(1,5) ¡ay!// no sé no sé///(1) es: otra cosa ya///(1,5) y:///(1) bueno pues que yo no lo haría///(1) creo

Una vez recogidas, seleccionadas y clasificadas las funciones que se van a enseñar en el aula de español, no debe olvidarse, en ningún caso, la comparación intercultural o inter-comunicativa del repertorio establecido (Cestero, 1998, 7). También, será necesario su tratamiento por niveles "en consonancia siempre con el plan curricular específico con el que estemos trabajando" y su integración en la enseñanza de otros signos fonéticos, gramaticales, léxicos, pragmáticos o conversacionales (Cestero, 2007, 20).

\section{PROPUESTA METODOLÓGICA PARA EL TRATAMIENTO CURRICULAR DEL SILENCIO EN EL AULA DE ELE}

La introducción en el aula de los signos no verbales, en palabras de Cestero $(2007,20)$, no tiene por qué suponer un problema, pues debe hacerse por niveles, ordenando los signos de acuerdo, "en primer lugar, a su mayor o menor funcionalidad, en segundo lugar, a su mayor o menor frecuencia de uso y, por último, a la mayor o menor dificultad que entraña su realización". Asimismo, tendrá que realizarse de forma integrada con el resto de contenidos de la programación curricular (Cestero, 2007, 20-21):

Así, por ejemplo, cuando enseñemos en los primeros temas de los primeros niveles signos verbales con usos sociales, tales como las fórmulas verbales de saludo y de despedida, enseñaremos también gestos y elementos cuasi-léxicos que se utilizan para realizar la misma función (un beso en cada mejilla en contextos informales, el estrechamiento de mano en contextos formales y los distintos gestos de levantamiento de mano o los signos paralingüísticos Ey, Eeh, Chss... que pueden utilizarse como saludos o despedidas de paso). De la misma manera, junto con la 
enseñanza de elementos verbales de relación y organización discursiva, enseñaremos los gestos que se combinan con ellos o que pueden cumplir la misma función estructuradora de discurso, sirva de ejemplo el estiramiento de dedos (comenzando por el pulgar) para ordenar los contenidos que se expondrán a continuación, acompañando o sustituyendo a Primero/En primer lugar..., Después/En segundo lugar..., Por último/En tercer lugar... Por último, al enseñar y ejercitar, por ejemplo, cómo identificar personas u objetos o cómo describir personas, lugares, objetos, estados... trabajaremos conjuntamente la expresión verbal, paralingüística y quinésica (con las informaciones proxémicas y cronémicas pertinentes).

Lo mismo deberá ocurrir cuando lo que se traten de explicar sean las funciones comunicativas del silencio en el aula de ELE. Su tratamiento en la clase de español tendrá una finalidad integradora y deberá responder a la necesidad de mostrar todos los exponentes verbales y no verbales de una determinada función comunicativa de la lengua extranjera. Asimismo, se podrá hacer alusión a los actos silenciosos y explicar algunos de sus valores sociales cuando se trabajen los componentes culturales de la lengua que se está adquiriendo o también podrán explicarse sus valores sociopragmáticos cuando se presenten los contenidos pragmáticos de la lengua meta, pues como se sabe los signos verbales y no verbales cuentan con distintas connotaciones positivas o negativas en todas las culturas que se relacionan habitualmente con los comportamientos considerados corteses o descorteses por el grupo de hablantes (Camargo y Méndez, 2013).

Dicho lo anterior y basándonos en la idea de nivelación de los signos no verbales sugerida por Cestero $(1998,1999,2004,2007)$ y en la taxonomía presentada en el apartado anterior, se presenta a continuación una propuesta para añadir de manera integrada y nivelada el estudio de los actos silenciosos en las programaciones curriculares de lenguas extranjeras (Méndez, en prensa):

\section{APROXIMACIÓN A LOS ACTOS SILENCIOSOS}

PROFUNDIZACIÓN EN LOS ACTOS SILENCIOSOS
Niveles elementales o de usuario básico (A1 y A2): trabajar únicamente con funciones del silencio de uso frecuente en la cultura española, principalmente de carácter discursivo, estructurador y psicológico, que sean sencillas y que aparezcan habitualmente acompañadas de otros signos no verbales como gestos, posturas o maneras que ayuden a su interpretación: intensificación, atenuación, afirmación, prudencia, situación emocional extrema, desconocimiento, reflexión, desacuerdo, cesión de turno mediado...

Niveles intermedios o de usuario independiente (B1 y $B 2)$ : se amplía el repertorio a funciones que requieran de más referentes culturales, saberes y comportamientos socioculturales o que necesiten de un mejor manejo de las estructuras de la conversación. Se 
incluyen aquí principalmente las funciones de carácter normativo y las dinamizadoras de la conversación: silencios rutinarios, institucionales, jerárquicos, de petición de apoyo, de cambio de tema, por temas tabú...

CONSOLIDACIÓN DE LOS ACTOS SILENCIOSOS
Niveles superiores o de usuario competente (Cl y C2): se completará la enseñanza del silencio con aquellas funciones que requieran un proceso inferencial mayor para el hablante y que, por tanto, resulten más complicadas de identificar por un hablante no nativo, ya sea porque enmascaran o transgreden el sentido denotativo del mensaje, ya sea porque son errores comunicativos involuntarios o choques intencionados: resistencia, desafío, enfado, falta de acuerdo en el turno de palabra, choque intercultural, engaño o enmascaramiento...

Metodología para el tratamiento curricular del silencio en el aula de ELE (Méndez, en prensa)

Por otra parte, para organizar, secuenciar y llevar a cabo la enseñanza del silencio en el aula de ELE proponemos seguir el plan de trabajo que plantea Cestero $(2004,611)$ y que consiste en (1) presentar de forma explícita e implícita los signos no verbales, (2) realizar actividades encaminadas al aprendizaje de signos no verbales, (3) realizar actividades diseñadas para reforzar el aprendizaje de estos signos no verbales y (4) realizar actividades para conseguir la adquisición de los de los signos no verbales. Estas directrices -unidas al precepto de presentación-práctica-producción de los contenidos que siguen muchos de los últimos estudios en el ámbito de la enseñanza de lenguas y, muy especialmente, aquellos que se basan en el enfoque por tareas- nos llevan a presentar la siguiente planificación para la introducción del silencio en el aula de ELE:

1) Se presentarán los silencios - establecidos para el nivel- centrando la atención en su significado, función comunicativa y valor sociocultural.

2) Se practicarán los silencios, en primer lugar, de forma controlada y a través de actividades dirigidas por el profesor para empezar a conocer los usos del silencio en la cultura española y, a continuación, a través de actividades más libres pensadas para que el estudiante empiece a practicar los actos silenciosos de forma más autónoma. 
3) Se producirán los silencios a partir de actividades abiertas que permitan al estudiante aplicar y retener las funciones comunicativas del silencio aprendidas y que posibiliten su adquisición en la lengua extranjera.

Con esta metodología queda claro que el objetivo del profesor de ELE debe ser el de presentar los actos silenciosos de forma clara y concreta. Para hacerlo podrá servirse de imágenes o fotografías unívocas, materiales audiovisuales preseleccionados, corpus de textos o conversaciones cotidianas... que simplifiquen y faciliten la asimilación y práctica de los signos no verbales (Poyatos, 1994; Cestero, 1999; Méndez, en prensa). Poyatos (1994, 2002, 2006) explica que "son muy diversas las actividades que pueden desarrollarse para que los alumnos vean, oigan, practiquen y, por último, aprendan los comportamientos verbales y no verbales con suficiente fluidez" (Poyatos, 2006, 43). Entre las que propone el autor, destacan las demostraciones del profesor, la práctica de cognados y falsos cognados, las cintas de audio o vídeo como prueba de comprensión, el material del libro o las escenificaciones teatrales (Poyatos, 2006, 43-44).

Por otra parte, el profesor deberá conocer algunos aspectos culturales de los países de procedencia de sus alumnos con el fin de poder hacer frente a las dificultades de adquisición de la lengua meta que puedan surgir en el aula (Poyatos, 2006, 32). Atender esas diferencias interculturales en el aula, permitirá a los estudiante tomar conciencia de las similitudes y diferencias existentes entre las funciones comunicativas de los silencios en la cultura española y en su cultura de origen y dar mayor importancia a su aprendizaje en el aula de ELE. Como se ha comentado, el desconocimiento de las variaciones en el uso del silencio en las distintas culturas puede llevar al estudiante a cometer errores pragmáticos que en una interacción real pueden ser fuente de malentendidos, presuposiciones y choques culturales. Por ende, será necesario que el tratamiento curricular de los actos silenciosos en las programaciones de enseñanza de lenguas extranjeras atienda también los elementos comunes y no comunes entre los signos no verbales de las distintas lenguas y culturas.

En definitiva, lo que ha de transmitirse a los estudiantes es que los silencios son elementos relativos, sometidos a la variación cultural que sirven a los hablantes para comunicarse, pues intensifican, indican reflexión, prudencia, desconocimiento, cesión del turno de palabra, desacuerdo... Y que estos elementos pueden aparecer solos o junto a otros signos verbales y no verbales, bien significando por sí mismos, bien apoyando a los signos junto a los que aparecen (Poyatos, 1994; Cestero, 1999; Camargo y Méndez, 2013).

A continuación, se presentan algunas ideas aplicables a la preparación de actividades para trabajar el silencio en la clase de segundas lenguas:

1. La utilización de materiales reales (imágenes, vídeos, corpus de conversaciones, cómics, entrevistas, etc.) es fundamental en la creación de 
actividades. Lo ideal es que el tratamiento de las funciones no verbales del lenguaje se haga a través de elementos cotidianos de la vida real y que estas funciones paralingüísticas estén, a su vez, en conjunción con las funciones comunicativas verbales del mismo tipo.

2. Si se plantean actividades para un grupo heterogéneo, con necesidades y vivencias personales diferentes y con nacionalidades diversas, los ejercicios que se propongan han de tener un carácter variado. El punto de partida debe ser "la necesidad de motivar" y la "participación activa del estudiante" para presentar una gama diversa y dinámica de actividades de posible aplicación real. El "análisis de la interlengua" y sus correspondientes errores también han de estar presentes en el repertorio de ejercicios.

3. Para empezar, se ha de ofrecer un conjunto de actividades de presentación, a modo de toma de contacto con el tema que nos ocupa: el silencio en la cultura española. En ellas se puede recurrir a trabajar con elementos muy presentes en la sociedad actual como son las entrevistas, los blogs, las webs de viajes, artículos de opinión, etc. El desarrollo de las cuatro destrezas (comprensión y expresión oral y escrita) deben realizarse de forma integrada. Es por ello que conviene que cada actividad requiera al alumno que haga varias tareas a la vez: leer y escribir; escuchar y hablar; escuchar y escribir; leer y hablar, etc.

4. Una vez presentadas en el aula las funciones comunicativas del silencio, se deben realizar actividades de práctica. Estas tareas posibilitadoras deben estar diseñadas de más controladas a más libres. La motivación del alumno, su implicación en el aprendizaje y el análisis de su interlengua deberán tenerse muy en cuenta con el fin de la correcta adquisición de la competencia comunicativa y de los contenidos que se están tratando. Las actividades se centrarán en la asimilación y práctica de las funciones y usos pragmáticos del silencio. Para ello puede recurrirse a la reproducción de materiales audiovisuales y su posterior análisis, así como al uso otros materiales como los cómics, los corpus conversacionales y los textos publicitarios.

5. Una vez presentado y practicado el silencio llega el momento de su producción autónoma. En este sentido, se puede elaborar una tarea final como consecución de todo el proceso que permita al alumno retener y aplicar los contenidos de las actividades anteriores. Un ejemplo de actividad sería proponer a los alumnos que, a partir de una acción de la vida real como es dar información o expresar conocimientos sobre un tema, realicen una simulación de una clase de español en la que tiene que poner en práctica todo lo aprendido y trasmitir esa información a unos hipotéticos estudiantes de español recién llegados y que, como ellos antes de trabajar el silencio en clase, no conocen el funcionamiento del silencio en España. El procedimiento puede realizarse a partir de la integración de las cuatro 
destrezas y con la ayuda de algunas indicaciones que aparezcan en la instrucción de la actividad, así se animará al alumno a que se inicie en el mundo de las representaciones o "role plays" que, sin duda, tanto favorecen la adquisición de las lenguas. El tiempo disponible para realizar la actividad podría ser de 1 hora (o algo más, eso dependerá del nivel de conocimientos de los estudiantes y del tipo de agrupación que se proponga para llevar a cabo el ejercicio). Lo recomendable es que dedique la mitad del tiempo o un poco más a la elaboración de la propuesta y que el resto se utilice para su puesta en práctica.

\section{CONCLUSIONES}

Ya se ha visto cómo la completa adquisición de la competencia comunicativa requiere la incorporación de los signos no verbales a la enseñanza-aprendizaje de la lengua extranjera. La primacía de las estructuras verbales y no verbales propias de los estudiantes de lenguas extranjeras llevan frecuentemente a estos hablantes a realizar transferencias entre su lengua materna ( $u$ otra/s que conocen) y la lengua meta. Estas cuestiones desembocan en habituales presuposiciones o sobreentendidos sobre estos signos que conducen al error. Diversos autores han abogado por la inclusión de los signos no verbales en el aula de ELE y han propuesto metodologías, técnicas y recursos de gran utilizad para su enseñanza (Poyatos, 1994, 2002, 2006, 2012; Cestero, 1998, 1999, 2004, 2007). En los últimos tiempos, además, la comunicación no verbal ha contado con el reconocimiento institucional en ciertos planes curriculares (MCER y PCIC), cuestión que ha facilitado en gran medida el tratamiento sobre todo de la quinésica, aunque también de algunos signos paralingüísticos, proxémicos y cronémicos en las programaciones de aula (Cestero, 2007).

El silencio, sin embargo, no ha corrido la misma suerte y ha sido ignorado en los planteamientos pedagógicos $\mathrm{y}$, por tanto, su tratamiento ha estado excluido en la clase de español. Entre las causas que lo han llevado a esta situación, se han destacado aquí la escasa tradición en el estudio comunicativo del silencio, la gran diversidad taxonómica actual, la falta de una metodología clara y la dificultad de interpretación que, en ocasiones, presentan estos signos. Por todo ello, a la hora de determinar qué silencios se van a enseñar, habrá que partir de una serie de criterios previos para su selección -partiendo del nivel del alumno, del currículo establecido y de los objetivos planteados en él- con el fin de que la enseñanza de los actos silenciosos se ajuste a las necesidades y posibilidades de los estudiantes.

Para abordar algunas de estas cuestiones y posibilitar su incorporación al aula de ELE, se ha presentado aquí una clasificación de las funciones comunicativas del silencio en la cultura española, proveniente de estudios de corpus conversacionales, que sea aplicable a la clase de español y se ha propuesto su tratamiento por niveles (aproximación, profundización y consolidación) a partir de una metodología centrada en la presentación, la práctica y la producción de los actos silenciosos en 
el aula de español como lengua extranjera. Por último, se han presentado algunas ideas concretas para su posible didáctica en el aula de ELE.

\section{REFERENCIAS BIBLIOGRÁFICAS}

AMBADIANG, Théophile y GARCÍA PAREJO, Isabel (2006): "La cultura lingüística y el componente cultural en la enseñanza de lenguas no maternas: observaciones sobre algunos paradigmas de la competencia cultural, en Didáctica (Lengua y Literatura), 18, 61-92. Disponible en Internet: http://revistas.ucm.es/index.php/DIDA/article/download/DIDA0606110061 A/1 9152 [Consulta: 11 de agosto de 2014].

BILMES, Jack (1994): "Constituting silence: Life in the world of total meaning", en Semiótica, 98, 1-2, 73-87.

BROWN, Penelope y LEVINSON, Stephen [(1987) 1978]: Politeness. Some universals in language usage, Cambridge, Cambridge University Press.

CAMARGO FERNÁNDEZ, Laura (2006): "Cuestiones metodológicas de la investigación en pragmática: ¿de dónde proceden nuestros ejemplos?”, en Orientaciones Metodológicas, Actas I Congreso internacional de filología hispánica: jóvenes investigadores, En CALZÓN GARCÍA, J. A. et al. (Eds.), Oviedo, Universidad de Oviedo, 81-92.

CAMARGO FERNÁNDEZ, Laura y MÉNDEZ GUERRERO, Beatriz (2013): "Los actos silenciosos en la conversación de los jóvenes españoles: ¿(des)cortesía o "anticortesía"?, en ELUA, 27, 89-120. Disponible en Internet: http://rua.ua.es/dspace/bitstream/10045/36624/1/ELUA_27_04.pdf [Consulta: 16 de marzo de 2014].

CAMARGO FERNÁNDEZ, Laura y MÉNDEZ GUERRERO, Beatriz (en prensa): "La pragmática del silencio en la conversación en español. Propuesta taxonómica a partir de conversaciones coloquiales", en Sintagma, 26.

CESTERO MANCERA, Ana María (coord.) (1998): Estudios de comunicación no verbal, Madrid, Edinumen.

CESTERO MANCERA, Ana María (1999a): Comunicación no verbal y enseñanza de lenguas extranjeras, Madrid, Arco/Libros.

CESTERO MANCERA, Ana María (2000a): El intercambio de turnos de habla en la conversación, Alcalá de Henares, Servicio de Publicaciones de la Universidad de Alcalá.

CESTERO MANCERA, Ana María (2004): "La comunicación no verbal", en Vademécum para la formación de profesores. Enseñar español como segunda lengua/lengua extranjera, SÁNCHEZ LOBATO, J. y SANTOS GARGALLO, I. (Eds.), Madrid, SGEL, 593-616.

CESTERO MANCERA, Ana María (2006): "La comunicación no verbal y el estudio de su incidencia en fenómenos discursivos como la ironía", en ELUA, 20, 57-77. Disponible en Internet: 
http://rua.ua.es/dspace/bitstream/10045/6074/1/ELUA_20_03.pdf [Consulta: 16 de marzo de 2014].

CESTERO MANCERA, Ana María (2007): "La comunicación no verbal en el Plan Curricular del Instituto Cervantes. Niveles de Referencia", en Frecuencia $L, 34,15-21$.

CONSEJO DE EUROPA (2002). Marco común europeo de referencia para las lenguas: aprendizaje, enseñanza, evaluación, Madrid, Secretaría General Técnica del MECD-Subdirección General de Información y Publicaciones / Anaya (Traducción al español del Instituto Cervantes). Disponible en Internet: http://cvc.cervantes.es/ensenanza/biblioteca_ele/marco/cvc_mer.pdf [Consulta: 16 de marzo de 2014].

CONTRERAS FERNÁNDEZ, Josefa (2008): "Conversational silence and face in two sociocultural contexts", en Pragmatics: A quarterly journal of the international pragmatic association, 18, 4, 707-728. Disponible en Internet: http://elanguage.net/journals/pragmatics/article/view/587/508 [Consulta: 16 de marzo de 2014].

EPHRATT, Michal (2008): "The functions of silence", en Journal of pragmatics, 40, 1909-1938.

ESCANDELL VIDAL, María Victoria (2011): "La pragmática", en Invitación a la lingüistica, ESCANDELL VIDAL, M. V. y MARRERO AGUIAR, V. (Eds.), Madrid, Centro de Estudios Ramón Areces, 243-272.

GALLARDO PAULS, Beatriz (1993): "La transición entre turnos conversacionales: silencios, solapamientos e interrupciones", en Contextos, 11, 21-22, 189-220. Disponible en Internet: http://www.uv.es/pauls/silencios.PDF [Consulta: 16 de marzo de 2014].

GUTIÉRREZ QUINTANA, Esther (2007): Enseñar español desde un enfoque funcional, Madrid, Arco/Libros.

HAVERKATE, Henk (1994): La cortesía verbal. Estudio pragmalingüistico, Madrid, Gredos.

INSTITUTO CERVANTES (2006). Plan curricular del Instituto Cervantes. Niveles de referencia para el español, 3 volúmenes, Madrid, Instituto Cervantes-Biblioteca Nueva.

JAWORSKI, Adam (1993): The power of silence. Social and pragmatic perspectives, Newbury Park, SAGE.

KURZON, Dennis (1997): Discourse of silence, Amsterdam, John Benjamins.

LEONETTI JUNGL, Manuel (2008): "Gramática y pragmática", en Frecuencia-L, 35, 3-9.

MATEU SERRA, Rosa María (2001): El lugar del silencio en el proceso de la comunicación, Lleida, Universitat de Lleida. Disponible en Internet: http://www.tdx.cat/handle/10803/8173 [Consulta: 16 de marzo de 2014].

MÉNDEZ GUERRERO, Beatriz (2011): ¿Quien calla otorga? Funciones del silencio y su relación con la variable género, Palma de Mallorca, Biblioteca 
Digital de la Universitat de les Illes Balears. Disponible en Internet: http://ibdigital.uib.es/greenstone/collect/memoriesUIB/import/Mendez_Guerrer o_Beatriz.pdf [Consulta: 16 de marzo de 2014].

MÉNDEZ GUERRERO, Beatriz (2013a): "El silencio a examen: ¿son (des)corteses o "anticorteses" nuestros silencios?, en Jóvenes aportaciones a la investigación lingüistica, GONZÁLEZ SANZ, M. (Ed.), Sevilla, Servicio de Publicaciones de la Universidad de Sevilla.

MÉNDEZ GUERRERO, Beatriz (2013b): "El silencio en la conversación española. Reflexiones teórico-metodológicas", en Estudios Interlingüisticos, 1, 67-86. Disponible en Internet: $\mathrm{http} / /$ www.asociacionjoveneslinguistas.com/files/mendezguerrero.pdf [Consulta: 11 de agosto de 2014].

MÉNDEZ GUERRERO, Beatriz (en prensa): “¡Mira quién calla! La didáctica del silencio en el aula de ELE", en Revista Internacional de Lenguas Extranjera (RILE), 3, Suplemento.

MORSBACH, Helmut (1988): "Silence and stillness in Japanese nonverbal communication", en Cross-Cultural Perspectives in nonverbal communication, POYATOS, F. (Ed.), Lewiston, Hogrefe, 201-215.

NAKANE, Ikuko (2005): "Negotiating silence and speech in the classroom", en Multilingua, 24, 75-100.

PRESEEA (2008): "Marcas y etiquetas mínimas obligatorias". Versión 1.2. 31-012008.

Disponible

en

Internet:

$\mathrm{http} / /$ preseea.linguas.net/portals/0/metodologia/marcas etiquetas_minimas_obl igatorias_1_2.pdf [Consulta: 11 de agosto de 2014].

POYATOS, Fernando (1994): La comunicación no verbal. Cultura, lenguaje y conversación, Madrid, Istmo.

POYATOS, Fernando (2002): Nonverbal communication across disciplines, Vol. I: Culture, sensory interaction, speech, conversation, Amsterdam/Filadelfia, John Benjamins.

POYATOS, Fernando (2006): "La enseñanza del español a extranjeros a través de los estudios de comunicación no verbal", en Lingüística aplicada a la enseñanza de español como lengua extranjera: desarrollos recientes, CESTERO MANCERA, A. M. (Ed.), Alcalá de Henares, Servicio de Publicaciones de la Universidad de Alcalá, 27-46.

POYATOS, Fernando (2012): "La integración curricular de la Comunicación No Verbal en la Enseñanza Primaria y en la Secundaria: para el enriquecimiento académico y vivencial del alumno", en Didáctica. (Lengua y Literatura), Publicaciones Universidad Complutense, 24, 291-316. Disponible en Internet: http://dx.doi.org/10.5209/rev_DIDA.2012.v24.39928 [Consulta: 16 de marzo de 2014]. 
SACKS, Harvey, SCHEGLOFF, Emanuel. A. y JEFFERSON, Gail (1974): "A simplest systematics for the organization of turn-taking for conversation", en Language, 50, 696-735.

SAJAVAARA, Kari y LEHTONEN, Jaakko (1997): “The silent Finn revisited", en Silence: Interdisciplinary perspective, JAWORSKI, A. (Ed.), Berlin, Mouton de Gruyter, 263-283.

SAVILLE-TROIKE, Muriel (1985): "The place of silence in an integrated theory of communication", en Perspectives on silence, TANNEN, D. y SAVILLETROIKE, M. (Eds.), Norwood, Alex Publishing Corporation, 3-18.

SIFIANOU, Maria (1997): "Silence and politeness", en Silence. Interdisciplinary perspectives, JAWORSKI, A. (Ed.), Berlin/New York, Mouton de Gruyter, 6384.

VIVAS MÁRQUEZ, Julia (2011): El relativismo cultural del silencio. Una propuesta para el aula de ELE desde la pragmática intercultural, Salamanca, Universidad de Salamanca. Disponible en Internet: http://marcoele.com/descargas/13/vivas-silencio.pdf [Consulta: 16 de marzo de 2014]. 